\title{
Editorial
}

\section{EDIÇÃO ESPECIAL: GESTÃO DE BACIAS HIDROGRÁFICAS}

SPECIAL EDITION: RIVER BASINS MANAGEMENT

\section{Caros leitores,}

É com entusiasmo e satisfação que apresentamos esta edição da Revista Brasileira de Ciências Ambientais dedicada ao tema gestão de bacias hidrográficas. Este número é decorrente das discussões realizadas na III Conferência Participativa em Gestão de Reservatórios e Bacias Hidrográficas, ocorrida em 2019 no Centro de Tecnologia e Geociências da Universidade Federal de Pernambuco, ocasião em que foi lançado o livro Gestão de bacias hidrográficas e sustentabilidade, publicado pela Editora Manole. O evento reuniu pesquisadores e profissionais de diversas instituições e suscitou o debate em torno da necessidade de divulgação científica de pesquisas acadêmicas qualificadas sobre o tema. A partir de então, fez-se um esforço coletivo a fim de disponibilizar à comunidade acadêmica e aos profissionais que atuam na área uma edição especial com experiências que abordassem múltiplos aspectos da sustentabilidade em bacias hidrográficas.

Nessa perspectiva, as análises desenvolvidas nos artigos contemplados nesta edição partem do viés interdisciplinar e apresentam pesquisas de várias partes do país, formando um mosaico de experiências envolvendo os recursos hídricos e seus usos múltiplos. Considerando a bacia hidrográfica como unidade de planejamento e gestão, os textos discutem questões que transitam entre políticas ambientais, gestão integrada de recursos hídricos, governança, previsão de cenários considerando as mudanças climáticas, incluindo apresentações de estudo de casos. Não se pretende esgotar a temática, mas evidenciar o que tem sido produzido no âmbito das ciências ambientais, que pode contribuir na otimização dos trabalhos de instituições do poder público, de ensino e pesquisa, juntamente com organizações não governamentais.

Discutir essa questão de modo interdisciplinar, como nos propusemos a fazer, poderá trazer grandes avanços para as ciências ambientais e, particularmente, à gestão de recursos hídricos no contexto atual, em que caminhamos visando ao horizonte postulado pelos Objetivos de Desenvolvimento Sustentável propostos na Agenda 2030, estabelecida pela Organização das Nações Unidas em 2015. Nesse sentido, a ciência é basilar e tem muito a contribuir.

Desejamos a todos proveitosa leitura,

Maria do Carmo Sobral

Editora Convidada.

Universidade Federal de Pernambuco - Recife (PE), Brasil.

E-mail: mariadocarmo.sobral@gmail.com 